\title{
SCNS. 17. Chronic opioid administration induces up-regulation of $\mu$ opioid receptors in descending pain facilitatory areas of the brain
}

\author{
CARACAS, P., COSTA, A.T, CARVALHO, P., TAVARES I., MARTINS I.
}

Department of Experimental Biology, Faculty of Medicine of Oporto and IBMC, Porto, Portugal

Introduction: Opiate analgesics remain the primary source of pain relief in conditions ranging from moderate to severe postoperative and chronic pain. Chronic opioid consumption induces paradoxical hyperalgesia (opioid-induced hyperalgesia; $\mathrm{OlH}$ ). $\mathrm{OlH}$ is characterized by hypersensitivity to innocuous or noxious stimuli during sustained opiate administration, and is recognized in clinical and pre-clinical settings. The mechanisms proposed to be essential for the development of OlH include neuroadaptive alterations in the pain modulatory circuitry and activation of supraspinal pain facilitatory pathways but the exact underlying mechanisms remain unknown. Objectives: Here we studied the effects of continuous morphine exposure in the expression of $\mu$ opioid receptors (MOR) in 3 medullary areas involved in descending pain modulation. The dorsal reticular nucleus (DRt), exclusively involved in pain facilitation; the rostral ventromedial medulla (RVM), involved both in facilitation and inhibition; and the caudal ventrolateral medulla (VLM) mainly involved in pain inhibition. Methods: We used an experimental model of $\mathrm{OlH}$ consisting on the continuous infusion of morphine $\left(45 \mu \mathrm{g} \cdot \mathrm{\mu l}^{-1} \cdot \mathrm{h}^{-1}\right)$ for 7 days. On the last day of morphine infusion, the development of mechanical allodynia and thermal hyperalgesia was assessed by the von Frey and Hargreaves tests, respectively, and MOR expression was evaluated by immunohistochemistry. Male Wistar rats weighing 285-300g were anesthetized and the osmotic pumps for morphine delivery were implanted subcutaneously. The control group was implanted with osmotic pumps filled with saline. After behavioral evaluation, the animals were transcardially perfused, the brains were removed and serially cut. Medullary sections encompassing the DRt, RVM and VLM were processed for MOR immunodetection. Results: The continuous infusion of morphine resulted in the development of mechanical allodynia and thermal hyperalgesia. Morphine infusion also resulted in increased expression of MOR at the DRt and the RVM. MOR expression at the VLM was not altered. Our results indicate that chronic exposure to opiates up-regulates MOR expression in supraspinal pain facilitatory areas. This up-regulation is likely involved in plastic alterations of opioidergic circuitries leading to increased descending pain facilitation contributing thus to the paradoxical hyperalgesia. Conclusions: It is essential to extend such studies to other pain modulatory areas, in particular to descending inhibitory areas, in order to better establish whether prolonged opioid exposure induces alterations in the opioidergic circuitries of descending pain inhibitory areas.

\section{Funding: FCT/COMPTE project PTDC/SAU-NSC/110954/2009, IASP Early career Research Grant}

CARACAS, P.; COSTA, A.T; CARVALHO, P.; TAVARES, I.; MARTINS, I. 2013. Chronic opioid administration induces up-regulation of $\mu$ opioid receptors in descending pain facilitatory areas of the brain, p.27. In: Oriá, Reinaldo Barreto; Andrade, Geanne Matos de; Bruin, Veralice Meireles S. de. I International Symposium in Neuroscience Meeting [Blucher Neuroscience Proceedings n.1 v.1]. São Paulo: Blucher, 2014 http://dx.doi.org/10.5151/isnm-sine22 